\title{
$\$$ Research Square \\ Smile Intensity in Volleyball Players' Profile Photographs is Unrelated To Sports Performance
}

Patrycja Chwiłkowska ( $\square$ patchw1@amu.edu.pl)

Adam Mickiewicz University in Poznań

Maciej Behnke

Adam Mickiewicz University in Poznań

Lukasz Kaczmarek

Adam Mickiewicz University in Poznań

\section{Research Article}

Keywords: Smile intensity, volleyball players, photographs, sports performance

Posted Date: December 28th, 2021

DOI: https://doi.org/10.21203/rs.3.rs-1166042/v1

License: (1) This work is licensed under a Creative Commons Attribution 4.0 International License.

Read Full License 


\section{Abstract}

Studies indicated that individuals who tend to smile while taking their photographs tend to experience more positive emotions in their life and, in turn, achieve superior outcomes in several life domains. However, little is known whether positive emotionality revealed in players' profile photographs is related to sports performance. This study examined whether the smiling intensity in volleyball players' profiles (full, partial, and no smile) predicted individual (e.g., points scored, service, and reception errors) and team performance (winning a match). Building upon previous studies on positive emotions, we expected that players presenting full (Duchenne) smiles would achieve better results. We analyzed 196 volleyball players' profiles from the Polish highest-level professional league competition (PlusLiga). Raters coded smile intensity. Using three-level path models, we found that teams with more frequent Duchenne smiles performed as well as those who presented Duchenne smiles less often. We conclude that positive emotionality (as reflected in profile photo smiling) might be independent of male volleyball accomplishments.

\section{Introduction}

Positive emotions, and their expression, broaden people's mindsets, build lasting physical, psychological, social, and intellectual resources, and support optimal functioning [1]. In sports, positive emotions facilitate the performance in softball [2], basketball [3], sprint races [4], cross-country skiing [5], and esport [6].

Studying emotions in top-level athletes is challenging due to restricted access. One approach that overcomes limited access is the thin-slicing method, which uses segments of expressive behavior (e.g., smiles in publicly available photos) to predict meaningful life outcomes [7] [8] [9]. Of particular interest in the domain of emotions and performance is Duchenne smiling - a valid marker of positive emotionality signaling underlying positive emotions and positive affective traits such as interpersonal warmth [1] [10]. This type of smiling is characterized by muscle contraction around the mouth and the eyes. Duchenne smiles differ from fake or forced smiles that reflect intentions rather than experience or asymmetrical smiles that reflect contempt rather than positive emotions.

Research showed that individuals smiling in profile photos more intensely live longer [7], have higher life and marital satisfaction [11] [12] [13], are more competent [11], and achieve greater professional success [14]. Individuals who tend to smile in photos are also more caring for others, sociable, and interpersonally warm [11], factors that might be relevant to team sports performance. In sports, the research on smiling is limited. However, a recent experimental study indicated that smiling predicts running performance [15]. Nevertheless, no study to date tested whether profile photo smiling was predictive of sports success.

Considering the support for the facilitating role of positive emotions in sports, we aimed to investigate whether profile smiling data would suffice to predict athletes' performance. Building upon prior studies, 
we expected teams and individuals to perform better: 1) teams whose players express Duchenne smile more often to win more matches, and 2) players expressing Duchenne smile to achieve better results.

\section{Methods}

\section{Stimuli}

We used publicly available photos $(N=196)$ presenting Polish highest-level volleyball league (PlusLiga) male volleyball players in the $2019 / 2020$ season from all 14 PlusLiga teams. As for the player specialization, data involved 57 outside hitters, 54 middle blockers, 29 opposite hitters, 28 setters, and 28 liberos. Players' age ranged from 19 to 41 years $(M=28.38, S D=4.74)$. Players played from 1 to 25 matches in the season, resulting in 3596 cases of performance to analyze. A power analysis using G*Power 3.1 [16] indicated that 543 cases would allow detecting small effect sizes of $f^{2}=0.02$, with the power of 0.95 , for the regression coefficient.

\section{Measures}

\section{Smile Intensity}

Ten raters blind to the research questions evaluated players' profile pictures. Raters coded smiles using three categories - Duchenne smile (full smile), partial smile or asymmetrical smile, and no smile [14] [17]. A Duchenne smile is a facial expression characterized by the contraction of muscles around the mouth and the eyes that is closely related to the pleasant experience. A partial smile is a facial expression characterized by contraction of muscles only around the mouth, e.g., zygomaticus major, which draws the angle of the mouth upward. An asymmetrical smile is a facial expression characterized by the contraction of muscles around one side of the mouth, which draws the angle upward. Raters determined whether players presented no smile (coded as 0 ) vs. partial smile or asymmetrical smile (coded as 1 ) or Duchenne smile (coded as 2). The dominant rating for the raters was used as the smile intensity score for each photo. The interrater agreement was satisfactory (Krippendorff's $a=0.73$ ) [18].

\section{Sports Performance}

We used publicly available statistics from the PlusLiga website (www.plusliga.pl) to measure volleyball performance. We collected data across one season on the number of 1) sets and matches played by each player, 2) scored points, spike errors, perfect reception, reception errors, points scored blocking, service aces and service errors, and 3 ) match results (binary coded as defeat $=0$, win $=1$ ). We used the match results as a team performance indicator, and the scores, spike errors, perfect reception number, reception errors, points scored blocking, service aces, and service errors as the player performance indicators.

\section{Statistical strategy}

We tested whether smile intensity predicted volleyball performance using multivariate regression models in Mplus 8.5 [19] [20] [21]. We run five three-level models to account for within-player (level 2) and within- 
team (level 3) data dependency. The multivariate regression model regressed outcome variables specific for players' role (position) on dummy coded smiling intensity (no smile category as the reference category), controlling for age. For instance, we regressed scoring points performance (scored points, spike errors, and spiking number) on smile intensity among players whose primary role was in scoring points, i.e., opposite hitter, outside hitter, middle blocker/hitter controlling for the sum of spikes. We regressed reception performance (reception errors, number of perfect reception) on smile intensity among players who receive served balls, i.e., libero and outside hitter controlling for the sum of receptions. We regressed blocking performance (points scored blocking) on smile intensity among players whose primary role is scoring points, i.e., all players except libero. We regressed service performance (service aces and service errors) on smile intensity among players who serve the ball, i.e., all players except libero controlling for the sum of services. Furthermore, we ran the logistic regression model, regressing the match results (defeat vs. win) on the smiling intensity. We used the Bayesian correction estimator [20]. Significant coefficients are indicated by $95 \%$ confidence intervals that do not include zero. Data and scripts are available in supplementary materials.

\section{Results}

\section{Descriptive statistics}

Table 1 presents means, standard deviations, and the correlation matrix. Table S1 presents smiling distribution within teams (see Supplementary Tab. S1). Most volleyball players (66.3\%) smiled in their profile pictures, with $110(56.1 \%)$ athletes expressing partial or asymmetrical smiles, $20(10.2 \%)$ expressing a Duchenne smile, and 66 not smiling (33.7\%).

\section{Main analysis}

\section{Scoring Points Performance}

Players that expressed Duchenne smile had the same number of points, $\beta=.01,95 \% \mathrm{Cl}[-.16, .19]$, spike errors, $\beta=-.05,95 \% \mathrm{Cl}[-.14, .04]$, and number of spiking, $\beta=.03,95 \% \mathrm{Cl}[-.14, .21]$, compared to players that did not smile. Players who smiled partially or asymmetrically had the same number of points, $\beta=.02$, $95 \% \mathrm{Cl}[-.16, .20]$, spike errors, $\beta=-.04,95 \% \mathrm{Cl}[-.13, .05]$, and number of spiking, $\beta=.01,95 \% \mathrm{Cl}[-.18, .18]$ compared to players that did not smile.

\section{Reception Performance}

Players that expressed Duchenne smile had the same number of reception errors, $\beta=.14,95 \% \mathrm{Cl}[-.10$, $.44]$, and the number of perfect reception, $\beta=-.14,95 \% \mathrm{Cl}[-.33, .05]$, compared to players that did not smile. Players that smiled partially or asymmetrically had the same number of reception errors, $\beta=.07$, $95 \% \mathrm{Cl}[-.15, .33]$, and the number of perfect reception, $\beta=.08,95 \% \mathrm{Cl}[-.12, .29]$, compared to players that did not smile.

\section{Blocking Performance}


Players that expressed Duchenne smile had the same number of points scored blocking, $\beta=-.10,95 \% \mathrm{Cl}$ $[-.28, .07]$, compared to players that did not smile. Players who smiled partially or asymmetrically had the same number of points scored blocking, $\beta=-.07,95 \% \mathrm{Cl}[-.25, .10]$, compared to players who did not smile.

\section{Service Performance}

Players that smiled partially or asymmetrically had the same number of service aces, $\beta=-.05,95 \% \mathrm{Cl}$ $[-.19, .09]$, and the number of service errors, $\beta=-.06,95 \% \mathrm{Cl}[-.21, .11]$, compared to players that did not smile. Similarly, players that expressed Duchenne smile had the same number of service aces, $\beta=.02$, $95 \% \mathrm{Cl}[-.14, .17]$, and the number of service errors, $\beta=-.11,95 \% \mathrm{Cl}[-.27, .06]$, compared to players that did not smile.

\section{Team Performance}

Players who smiled partially or asymmetrically, $\beta=.04,95 \% \mathrm{Cl}[-.53, .53]$, or expressed Duchenne smiles, $\beta$ $=.02,95 \% \mathrm{Cl}[-.45, .58]$, won the same number of matches as players who did not smile on the photos.

\section{Discussion}

We examined smile intensity revealed in volleyball players' profile pictures as a marker of positive emotionality and related it to players' performance. We found that positive emotionality revealed in profile pictures was unrelated to the individual or team performance. These findings are the first to suggest that positive emotionality estimated from profile pictures does not predict volleyball performance. This adds to cumulative and complex evidence of how and to which extent emotions and their expression are related to sports outcomes. Players performed equally well whether they smiled or not. These findings add to the complexity of previous studies showing that smiling can hamper [22] or facilitate [15] sports performance. Our finding is a caveat because elicited positive emotions usually improve sports performance across many contexts [2] [3] [4] [5] [6]. However, our findings suggest that a happier facial expression revealed in a profile picture of volleyball players does not convey meaningful information that might predict sports outcomes.

We also found that team members' positive emotionality determined by the smiling expression did not influence the team's odds of winning or losing. Again, previous studies pointed out team-related positive emotionality as a predictor of successful team sports performance [23]. Thus, our findings reveal that accounting for smiling expressions disclosed on players' photos might be insufficient to understand team emotionality and predict their outcomes. Our findings add another perspective to the stream of research on smiles, emotions, and sports performance.

\section{Limitations and Future Directions}

The study had several limitations. First, we investigated photos exclusive to the PlusLiga players. Therefore, the results cannot be generalized to the whole discipline. Future studies might validate our 
findings with photos from different leagues (covering a variety of countries and cultures) focusing on the broader range of facial expressions.

Second, the strength of the relationship between smiles and performance outcomes depends on the study material. For instance, it is more significant when smiles are captured in films than in photos [24]. More accurate estimation of positive emotionality, e.g., video material, might provide different results [17] [25]. Future research might use publicly available brief video clips of specific game actions to assess the smile category in the wild. Furthermore, we cannot rule out the possibility that some players were instructed to pose in a specific way to present the photographer's artistic intention. Future studies might use players' photos from other sources (e.g., social media) that might be more representative of players' daily emotionality.

Third, the study is cross-sectional, and causality cannot be determined. For instance, we cannot distinguish whether achievements preceded or followed happier expressions. Research suggests that bidirectional influences are likely, i.e., achievements lead to happiness and happiness lead to achievements [26]. Future longitudinal studies might link photos taken before each match or action to establish to which extent the smile predicts or follows particular match results or both. Smiling might be more predictive of sports performance for photos taken close to the competition [22].

Finally, although the validity and accuracy of the thin-slicing methodology using profile photo smiles have been evidenced [7] [11] [14], inferring emotions based on facial movements is considered risky [27]. For decades, Duchenne smile was considered a genuine positive emotions indicator [1]. However, the latest studies undermine these findings [25] [27]. Our findings might favor these new theoretical approaches. The correspondence between facial movements and experiencing distinct emotions is often not straightforward [27]. Facial configurations are not "fingerprints" of emotional states regardless of individual, social and cultural context [27].

\section{Conclusions}

Our findings indicated that positive emotionality, determined via profile photos smiling analysis, is not related to volleyball performance. A major strength of this study is that we used publicly available objective data and documented how smiles manifest in players' official profile pictures and how this thin slice of expressive behavior is related to sports performance. A further examination of players' emotionality, e.g., emotions experienced across daily training or competitive contexts, might be necessary to learn more about the role of positive emotionality in volleyball.

\section{Declarations}

\section{Data Availability}

All data ("data_volley_smile.xlsx") and scripts ("syntax_volley_smile.txt") used for analysis are included in supplementary files. 


\section{Author contributions}

P. Ch. and L.D.K. designed research; P. Ch. wrote the original draft; all authors analyzed the results, interpreted the data, and reviewed the manuscript.

\section{Additional Information}

The author(s) declare no competing interests.

\section{References}

1. Fredrickson, B. L. (2013). Positive emotions broaden and build. In Advances in Experimental Social Psychology (Vol. 47, pp. 1-53). Academic Press. https://doi.org/10.1016/B978-0-12-407236-7.000012

2. Vast, R. L., Young, R. L., \& Thomas, P. R. (2010). Emotions in sport: Perceived effects on attention, concentration, and performance. Australian Psychologist, 45(2), 132-140. https://doi.org/10.1080/00050060903261538

3. Uphill, M., Groom, R., \& Jones, M. (2014). The influence of in-game emotions on basketball performance. European Journal of Sport Science, 14(1), 76-83. https://doi.org/10.1080/17461391.2012.729088

4. Rathschlag, M., \& Memmert, D. (2015). Self-generated emotions and their influence on sprint performance: An investigation of happiness and anxiety. Journal of Applied Sport Psychology, 27(2), 186-199. https://doi.org/10.1080/10413200.2014.974783

5. Moen, F., Myhre, K., \& Sandbakk, Ø., (2016). Associations between emotions and performance in cross-country skiing competitions. http://thesportjournal.org/article/associations-betweenemotions-and-performance-in-cross-country-skiing-competitions/

6. Behnke, M., Gross, J. J., \& Kaczmarek, L. D. (2020). The role of emotions in esports performance. Emotion. https://doi.org/10.1037/emo0000903

7. Abel, E. L., \& Kruger, M. L. (2010). Smile intensity in photographs predicts longevity. Psychological Science, 21(4), 542-544. https://doi.org/10.1177/0956797610363775

8. Kraus, M. W., \& Keltner, D. (2009). Signs of socioeconomic status: A thin-slicing approach. Psychological science, 20(1), 99-106. https://doi.org/10.1111/j.1467-9280.2008.02251.x

9. Mason, A. E., Sbarra, D. A., \& Mehl, M. R. (2010). Thin-slicing divorce: Thirty seconds of information predict changes in psychological adjustment over 90 days. Psychological Science, 21(10), 14201422. https://doi.org/10.1177/0956797610381507

10. Duchenne, B., \& Cuthbertson, R. A. (1990). The mechanism of human facial expression or an electrophysiological analysis of the expression of the emotions. In Ed. and Trans (Original work published 1862). Cambridge University Press. 
11. Harker, L., \& Keltner, D. (2001). Expressions of positive emotion in women's college yearbook pictures and their relationship to personality and life outcomes across adulthood. Journal of Personality and Social Psychology, 80(1), 112-124. https:// doi.org/10.1037/0022-3514.80.1.112

12. Hertenstein, M. J., Hansel, C. A., Butts, A. M., \& Hile, S. N. (2009). Smile intensity in photographs predicts divorce later in life. Motivation and Emotion, 33(2), 99-105. https://doi.org/10.1007/s11031-009-9124-6

13. Seder, J. P., \& Oishi, S. (2012). Intensity of smiling in Facebook photos predicts future life satisfaction. Social Psychological and Personality Science, 3(4), 407-413. https://doi.org/10.1177/1948550611424968

14. Kaczmarek, L. D., et al. (2018). Smile intensity in social networking profile photographs is related to greater scientific achievements. The Journal of Positive Psychology, 13(5), 435-439. https://doi.org/10.1080/17439760.2017.1326519

15. Brick, N. E., McElhinney, M. J., \& Metcalfe, R. S. (2018). The effects of facial expression and relaxation cues on movement economy, physiological, and perceptual responses during running. Psychology of Sport and Exercise, 34, 20-28. https://doi.org/10.1016/j.psychsport.2017.09.009

16. Faul, F., Erdfelder, E., Buchner, A., \& Lang, A. G. (2009). Statistical power analyses using G* Power 3.1: Tests for correlation and regression analyses. Behavior Research Methods, 41(4), 1149-1160. https://doi.org/10.3758/BRM.41.4.1149

17. Rychlowska, M., et al. (2017). Functional smiles: Tools for love, sympathy, and war. Psychological Science, 28(9), 1259-1270. https://doi.org/10.1177/0956797617706082

18. Hayes, A. F., \& Krippendorff, K. (2007). Answering the call for a standard reliability measure for coding data. Communication Methods and Measures, 1(1), 77-89. https://doi.org/10.1080/19312450709336664

19. Muthén, B., \& Muthén, L. (2017). Mplus (pp. 507-518). Chapman and Hall/CRC.

20. Muthén, B. (2010). Bayesian analysis in Mplus: A brief introduction.

21. Van de Schoot, R., et al. (2014). A gentle introduction to Bayesian analysis: Applications to developmental research. Child Development, 85(3), 842-860. https://doi.org/10.1111/cdev.12169

22. Kraus, M. W., \& Chen, T. W. D. (2013). A winning smile? Smile intensity, physical dominance, and fighter performance. Emotion, 13(2), 270.-279. DOI: 10.1037/a0030745

23. Campo, M., et al. (2019). Group-based emotions: Evidence for emotion-performance relationships in team sports. Research Quarterly for Exercise and Sport, 90(1), 54-63. https://doi.org/10.1080/02701367.2018.1563274

24. Gunnery, S. D., \& Ruben, M. A. (2016). Perceptions of Duchenne and non-Duchenne smiles: A metaanalysis. Cognition and Emotion, 30(3), 501-515. https://doi.org/10.1080/02699931.2015.1018817

25. Girard, J. M., Cohn, J. F., Yin, L., \& Morency, L. P. (2021). Reconsidering the Duchenne smile: Formalizing and testing hypotheses about eye constriction and positive emotion. Affective Science, 2(1), 32-47. https://doi.org/10.1007/s42761-020-00030-w 
26. Roberts, B. W., Caspi, A., \& Moffitt, T. E. (2003). Work experiences and personality development in young adulthood. Journal of Personality \& Social Psychology, 84, 582-593.

https://doi.org/10.1037/0022-3514.84.3.582

27. Barrett, L. F., Adolphs, R., Marsella, S., Martinez, A. M., \& Pollak, S. D. (2019). " Emotional expressions reconsidered: Challenges to inferring emotion from human facial movements": Corrigendum. https://doi.org/10.1177/1529100619889954

\section{Tables}

Table 1. Means, standard deviations, and correlations for all players.

\begin{tabular}{|c|c|c|c|c|c|c|c|c|c|c|c|}
\hline & $M$ & $S D$ & 1 & 2 & 3 & 4 & 5 & 6 & 7 & 8 & 9 \\
\hline 1. Points & 5.74 & 6.47 & & & & & & & & & \\
\hline 2. Spike errors & 0.60 & 1.05 & $.56^{\star \star}$ & & & & & & & & \\
\hline $\begin{array}{l}\text { 3. Spike } \\
\text { points }\end{array}$ & 9.15 & 10.75 & $.93^{* *}$ & $.67^{\star *}$ & & & & & & & \\
\hline $\begin{array}{l}\text { 4. Reception } \\
\text { errors }\end{array}$ & 0.45 & 0.92 & $.16^{* *}$ & $.16^{\star \star}$ & $.21^{\star *}$ & & & & & & \\
\hline $\begin{array}{l}\text { 5. Perfect } \\
\text { reception }\end{array}$ & 1.45 & 2.53 & $.20^{* *}$ & $.20^{\star *}$ & $.27^{* *}$ & $.52^{* *}$ & & & & & \\
\hline $\begin{array}{l}\text { 6. Block } \\
\text { points }\end{array}$ & 0.75 & 1.15 & $.52^{\star *}$ & $.18^{\star \star}$ & $.34^{\star *}$ & -.03 & $-.05^{\star \star}$ & & & & \\
\hline $\begin{array}{l}\text { 7. Service } \\
\text { aces }\end{array}$ & 0.45 & 0.87 & $.55^{\star \star}$ & $.27^{\star \star}$ & $.45^{\star \star}$ & $.09^{\star *}$ & $.11^{\star \star}$ & $.19^{\star *}$ & & & \\
\hline $\begin{array}{l}8 . \\
\text { Service errors }\end{array}$ & 1.41 & 1.57 & $.66^{\star *}$ & $.43^{\star \star}$ & $.65^{\star \star}$ & $.12^{\star *}$ & $.13^{\star \star}$ & $.34^{\star \star}$ & $.42^{\star *}$ & & \\
\hline $\begin{array}{l}\text { 9. Match } \\
\text { outcome }\end{array}$ & 0.50 & 0.50 & $.07^{\star *}$ & -.03 & .03 & $-.04^{*}$ & .02 & $.07^{\star \star}$ & $.06^{\star *}$ & .01 & \\
\hline $\begin{array}{l}\text { 10. Duchenne } \\
\text { smile }\end{array}$ & 0.12 & 0.32 & -.30 & $-.04^{*}$ & -.03 & .03 & -.01 & -.02 & $.04^{*}$ & -.02 & -.02 \\
\hline $\begin{array}{l}\text { 11. Partial } \\
\text { smile }\end{array}$ & 0.57 & 0.49 & -.01 & .01 & .01 & .03 & $.06^{\star \star}$ & -.01 & $-.04^{*}$ & -.02 & -.03 \\
\hline \multicolumn{12}{|c|}{ Note. Partial smile coded as $0=$ absent, $1=$ present; Duchenne smile coded as $0=$ absent, $1=$ present. } \\
\hline
\end{tabular}

\section{Supplementary Files}

This is a list of supplementary files associated with this preprint. Click to download. 
- SupplementaryMaterialsTableS1.docx

- syntaxvolleysmile.txt

- volley5.txt

- datavolleysmile.xlsx 